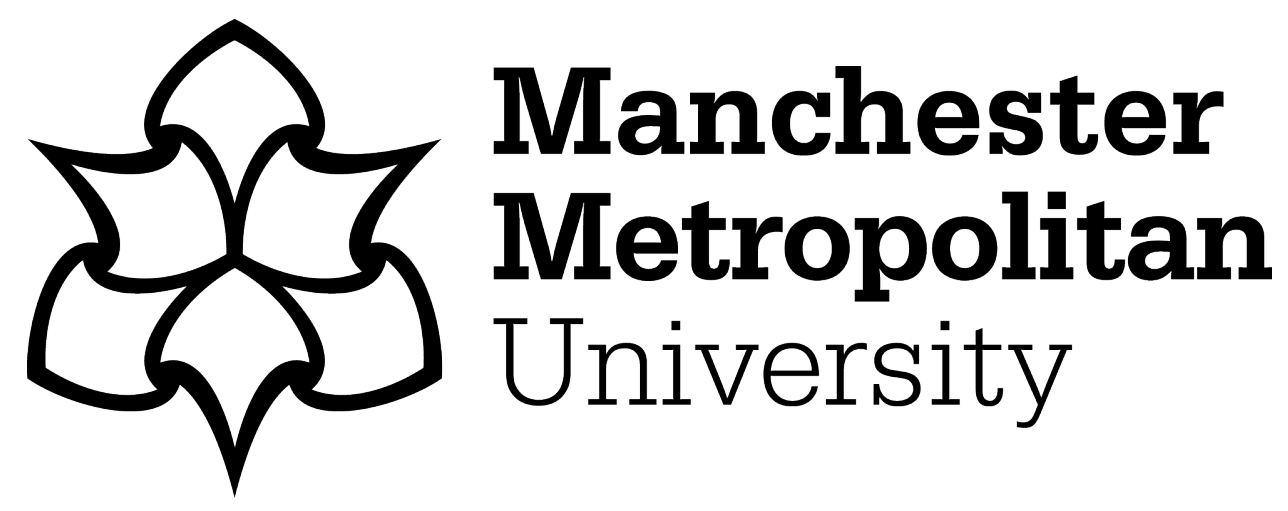

Stansfield, J ORCID logoORCID: https://orcid.org/0000-0002-3476-7002 (2020) Giving voice: an oral history of speech and language therapy. International Journal of Language and Communication Disorders, 55 (3). pp. 320-331. ISSN 1368-2822

Downloaded from: https://e-space.mmu.ac.uk/625185/

Version: Accepted Version

Publisher: Wiley

DOI: https://doi.org/10.1111/1460-6984.12520

Please cite the published version 


\section{Giving voice: an oral history of speech and language therapy}

Jois Stansfield

Manchester Metropolitan University

\section{Key words}

Speech and language therapy, oral history, professional lives, women.

\section{Structured abstract}

Background. The Royal College of Speech and Language Therapists (RCSLT) celebrates its $75^{\text {th }}$ anniversary in 2020 . Historical study of speech and language therapy (SLT) has been very limited. A small number of publications have traced the changes in the profession over time, but to date there has been no comprehensive work undertaken to gain an insight into the experiences of UK speech therapists who entered the newly formed profession after 1945.

Aims. The aim of this study was to use oral history methodology to explore the life stories of early members of the profession.

Methods \& Procedures. Participants were recruited through RCSLT networks. Interviews were held across England and Scotland. Conversations were audio recorded and analysed using thematic network analysis. Archive material was used to complement participants' narratives.

Outcomes \& Results. Participants were nineteen women qualifying between 1945 and 1968. Three global themes emerged: personal, professional and political stories. On a personal level, each reported steps towards autonomy and agency within the social constraints they experienced. Professionally all commented on the vast expansion in the range of identifiable clinical fields between 1945, when the first participant qualified and 2008 when the last participant retired. Politics and social 
policies impacted upon their lives and, sometimes to their surprise, participants found themselves campaigning politically in pursuit of fairness for their profession.

Conclusions \& Implications. This paper offers a unique insight into the challenges and achievements participants experienced over their careers as early practitioners in the UK profession.

\section{What this paper adds.}

Section 1: What is already known on this subject.

SLT professionalised in the twentieth century and formed a united professional body in 1945. The International Journal of Language and Communication Disorders (IJLCD), as the UK professional journal, gives indications of the changing emphasis in clinical work over the period since that date.

Section 2: What this study adds.

Autobiographical statements have been rare in the profession. This study presents a unique insight into the changes in the UK profession as reported by post-war practitioners.

Section 3: Clinical implications of this study.

The need for continued professional development over a career is underlined through the experiences of the participants in this study.

\section{Introduction}

SLT is a profession which developed slowly over the eighteenth and nineteenth centuries, and more rapidly throughout the twentieth century. Until 1991 the profession in the UK was known as 'speech therapy' and that term is used in this 
paper for the time period before 1991. Prior to the twentieth century, speech therapy in the UK was carried out predominantly by individuals interested in a combination of public speaking, rhetoric, elocution and correcting 'speech defects' (Rockey, 1980), but practitioners emerged from different professional backgrounds. Stammering aroused the attention of surgeons; the 'deaf and dumb' attracted interest from educationalists; neurologists began identifying areas of the brain involved in speech production, studying the results of stroke; and the physician John Wyllie wrote, lectured on and treated speech disorders. Thus by the end of the nineteenth century there was a body of knowledge and a small number of practitioners who were involved in the study and remediation of disorders of speech (Rockey, 1980). As a result, speech therapy gradually began to attain greater credibility.

Rockey's monograph is, to date, the only comprehensive outline of UK nineteenth century speech therapy. There is a little more literature available regarding the twentieth century, although here too historiography is sparse. Duchan hosts a website on history, especially of the US speech pathology profession, before 2000 (Duchan, n.d.). Eldridge (1968) gives an overview of speech therapy internationally up to 1966, considering parallel developments in the UK, eastern and western Europe and the US from 1900 to the mid-1960s. A third booklet (Robertson, Kersner and Davis, 1995) considers the UK experience from 1945-1995, while three papers trace the way in which this journal reflected the interests and concerns of the profession between 1935 and 2015 (Armstrong and Stansfield, 1996; Stansfield and Armstrong, 2016; Armstrong, Stansfield and Bloch, 2017). 
Four autobiographies give more personal pictures of speech therapy from the early 1920s to the 2000s (Brown, 1971; Wilkins, 1992; Hollingworth, 1993; Hewerdine, 2014). Most other information has appeared in the CST Bulletin as anecdotal stories of working life. From these various publications it can be seen that speech therapy followed a similar path to other emerging health professions: personal interest in helping those with impairments; academic development through self-study; formal training; and establishment of professional bodies (Witz, 1992).

As speech therapists started to organise, two competing professional organisations emerged: the Association of Teachers of Speech and Drama (Remedial Section) (AST) in 1934; and the British Society of Speech Therapists (BSST), which allied itself with the medical profession. The first national speech therapy register (NRMAS-ST), published by the British Medical Association, appeared in 1942. Listing only individuals with BSST qualifications, a total of 87 names appeared on this first register. The second edition of the register listed double the number of names, with qualifications from both BSST and AST being recognised, with a requirement that these would merge into a single body (Cope, 1945). Negotiations between these organisations were difficult, a result of professional jealousies as well as war time disruptions (Robertson et.al., 1995). They eventually amalgamated over the period 1943-45, with the foundation of CST on January 61945 (Editorial, 1945). This is the point at which participants in the current study began to enter the profession.

Oral history is an approach that has developed its own theoretical frameworks over the past forty years. The practice of oral history aims to give voice to previously 
unheard groups. It requires the researcher to take account of a range of elements which arise in interpersonal communication, such as concepts of the self, subjectivity and inter-subjectivity, performance and empowerment (Abrams, 2016; Yow, 2015). While some terminology may be unfamiliar, the underlying theories of oral history appear well suited to qualitative SLT research. The main thrust is to offer alternatives to written histories, which tend to be framed by the 'winners' of conflicts, the elite, the powerful, and predominantly by male authors. The impact of feminist theory on oral history, contesting as it does the neutrality and objectivity claimed by such traditional written histories, is unsurprising. Gluck, for example, identifies a female collaborative ethos and a recognition of the importance of personal standpoint and social relations, as having a comfortable fit with the approaches used in oral history (Gluck, 2013).

The aim of the current study was to use oral history methodology to explore the life stories of early members of the profession. The project was not intended to be gender based and indeed the majority of the narrators would neither identify themselves as feminists, nor powerless, with all demonstrating a strong sense of self and personal agency. All the participants were, however, women and their experiences were coloured by the social expectations of the times, which created both constraints and opportunities during their careers.

\section{Method}

The study adopted a mixed methods approach. Oral histories are taken as key primary sources. This enabled voices of individuals to be heard through 
collaboration between them and the researcher in a conversational format (Yow, 2015). RCSLT archival records were explored to relate the written professional records to the working experiences of the oral history participants.

\section{Procedure}

\section{Participants and recruitment}

The inclusion criterion was any speech therapist who had qualified before 1970. The aim was to gather information from a range of people who had qualified in the 1940s, 1950s and 1960s. An invitation letter, project outline and topic guide was circulated by gatekeepers to a sample of retired SLTs across the UK. Recruitment commenced via a retired SLT managers' network and continued through the membership office of RCSLT and by snowballing. The letter made it clear that only people who expressed an interest would be contacted.

\section{Interviews}

Interviews lasted from 40 minutes to almost two hours. The majority were recorded in the participants' homes, two in a university library, one at RCSLT headquarters and one in a local pub. Each interview was audio-recorded using an Olympus digital voice-recorder VIN-731PC, and the MP4 recording facility on a mobile phone. Written field notes were also taken.

\section{Transcription}

One audio recording was inaudible and was not transcribed, although information was drawn from field notes. The other interviews were transcribed professionally and edited by the researcher to ensure accuracy, especially of place names and 
technical terms. Transcripts were returned to participants for member-checking prior to analysis.

\section{Analysis}

Within oral history, analysis of an interview is disputed territory, with arguments about ownership of the narrative, co-construction and levels of privilege being claimed by authors from differing philosophical backgrounds (Shulman, 2015). In order to avoid imposing a researcher privilege of pre-conceived themes, thematic network analysis was used to code and develop themes inductively from the interview transcripts. This approach offers a transparent order of stages and replicability of the process (see Table 1), if not the outcome of analysis and allows for a visual representation of the global, organising and basic themes which emerge (Attride-Stirling, 2001).

Insert table 1 here

\section{Archival search}

Archive material including meeting minutes, discussion papers, review documents, speech therapy registers and copies of Bulletin and the Journal in its various guises, were used as adjuncts to the themes generated from the oral histories.

\section{Ethics}

Ethical approval was granted by the author's University Faculty Ethics Committee (approval no 16/1345). GDPR approval for archiving was sought from each participant retrospectively, as these regulations only came into place during the 
progress of the project. All materials are treated in accordance with the initial consents, as amended by individual responses to these retrospective requests.

\section{Results and discussion}

A total of twenty semi-structured interviews took place, geographically spread across England and Scotland. There were no volunteers from Ireland or Wales. One participant subsequently withdrew from the study, thus eighteen audio recordings and nineteen sets of field notes formed the data set for the study, with support from archival sources. Participants had qualified between 1945 and 1968 and were aged between 70 and 95 at the time of recording. For the purposes of reporting, each participant is assigned a pseudonym (see Table 2).

Insert table 2 about here

Three global themes emerged from these data, personal stories; professional stories and political stories. Figures 1 to 3 present the three thematic networks.

Global theme 1. Personal stories.

Figure 1 about here

\section{Class and gender}

The general experience of the participants in this study, was that speech therapy was seen as a suitable career for middle class girls in the post-World War Two era. 
Kingdon-Ward (1948: 200) suggested that it was appropriate for their 'cultural background, intellectual attainment, personality and general suitability'. Participants had joined a profession governed predominantly by women who had begun their careers in the 1920s and 1930s and career constraints were discussed in relation to social expectations of generation and gender.

Accent: The initial impression from speaking to the participants was that they came from middle class families: immediately on meeting, this related to spoken accent. Some of the English participants demonstrated 'Conservative Received Pronunciation (RP)', a characteristic today of older, upper-middle-class speakers, while all the others used a form of 'general RP', again suggesting this class background. The Scottish participants all used an 'educated Scots-English'.

Looking further, however, class was not all at first it had appeared, at least with regard to speech. AltheaC, with a 'Conservative RP' accent was categorical that she 'came from a working class family'. It became clear that at college, compliance with 'speech standards' was required, with any regional accent being 'corrected'. This was common to English and Scottish participants.

...when I trained, you had to achieve an RP accent, because it was considered ... that was universal, universal BBC. JessW.

They tried to iron out everybody's Scottish accent MillicentT. 
A ladylike career: Many of the participants, regardless of when they started to consider their futures, reported the lack of available information about careers. Comments such as: 'I'd never heard of speech therapy' AmandaC were common. Possibly as a result of the lack of information, it was not the first choice of career for several of the participants: 'I had thought about nursing, I had thought of being an almoner, and I had thought of being a physio, various things. I didn't want to be a teacher' JayD; 'the only thing I ever wanted to do was become a nurse' AbigailS. Three had started university or college education in different fields, but chosen to change track. Two however, had ulterior motives for studying speech therapy. JanetC for example was clear that she wanted to leave home, while MegD was an aspiring actress.

...you didn't get a grant to study something which was available in Aberdeen. Right? So, I explored what was not available in Aberdeen... JanetC.

I didn't want particularly to do speech therapy...I really wanted to go on the stage ...the college in Edinburgh was linked to the drama school and I thought there might be some way of transferring... MegD.

Word of mouth: Speech therapy was not well known or well understood in the 1940s and 1950s and only gradually became better known as the 1960s progressed. Surprisingly, in view of the very small numbers of speech therapists, four participants had family or friends who were in the profession, suggesting that word of mouth was mostly responsible for getting information. SallyK, who had been studying at university said: 
...a cousin of mine had been going to do it at the outbreak of war. But then she didn't, she became a Wren instead and escorted Churchill round the world. It was much more exciting ... [then] This friend wrote and sent me the prospectus which sounded a lot more interesting than what I was doing.

Several volunteered information about their parents' involvement in career choice, with social connections coming into play:

Apparently my father was in music, and she [head of the speech therapy school] was in speech and drama, and they had been away in a conference in Norway representing all the arts; and she knew him, and she just took me. UrsulaH.

...Sandra's father and my father played golf together. And my father was a GP in [town]... And he heard that Sandra was doing speech therapy. And I didn't want to follow Dad into medicine... SelmaM

Once they had located speech therapy, however, it appeared to many to be a perfect fit for them. JessW said 'I thought it combines my love of people and working on language, communication'; CarolS found that 'it was a mixture of medicine and English, both of which interested me'. Thus it reflected the academic subjects in which participants were interested.

\section{Society expects...}


Participants largely reflected acceptance of the social expectations of the time and their personal experiences were mediated by the presence or absence of marriage and children. Their wider personal experiences, however, demonstrated the ways in which they negotiated the personal and the professional throughout their lives, while retaining their adherence to societal expectations.

Good behaviour: College expectations were a surprise to some participants and this was especially noticeable in the Glasgow school. The founder was highly respected by many, however others found the experience very old-fashioned.

...suddenly I was thrust into a 'Miss Jean Brodie' set up. It was incredible. Quite unbelievable. We had to wear blazers with the colours round it and the proper scarf. JanetC.

in the middle of a psychology exam, for example, she called us all downstairs to take off our makeup; in the middle of a psychology exam. And I mean you just did it. UrsulaJ.

Other colleges appeared to have had a similar approach, demanding good behaviour and compliance with rules. Indeed, in the late 1950s, the examination rules included:

...to go and do your practical exam in a hat and gloves. JessW. 
On qualification, all participants reported a sense of freedom in their first posts, which reflected an unspoken sense of relief at no longer needing to comply with quite so many rules, although by this stage they also reported an inbuilt selfmonitoring in order to appear professional, for example:

You were mistress of your own world. ...I was in control. As long as I kept my statistics! JessW.

I packed two boys into the car, took them to [the next village] for the morning. And treated them there. I did check the car insurance first. MillicentT.

Home comes first: All but two of the participants had been married and most of these gave up or reduced their working hours at least for a time, even when they did not have children: 'I was busy being married', JayD. The majority appeared to accept that husbands and children had the first call upon their time and their speech therapy and domestic careers were organised to take account of this, at least until the children were well grown. In parallel with teaching in the 1950s and 1960s (Dyhouse, 2016), the rising number of training places only gradually increased the work-force, as women left the profession to have children. As a result, work was available for most when they wanted it:

there was a terrific shortage of us and they were almost out looking for us. ThelmaT. 
there was always part-time work available and that was a tremendous help. I did all sorts of computations to fit in with family life. LindaL.

The individuality that was reported, was, however, striking. Atypical home lives included JillC, who married late and continued her career. AltheaC was well established and continued working full time when she started her family: When I had the four of them [children], I had two nannies to help. Two participants reversed the gender roles for a time, supporting husbands who were studying: a challenging task, as speech therapy salaries were low.

Homes and families did not detract from personal aspirations for any of the participants. In the main, as the focus of the interviews was on speech therapy, most referred to their career aspirations and how they worked to achieve these. For some it was a wish to work with a particular client group:

...I also hankered after her job. I was interested in adults really CarolS.

...research into babies with deafness. [I] was talking about it up in Nottingham, with an ENT man there and he said..."Would you be interested to join us?" And I said, "Yes!" JillC.

For others, it was the wish to provide a good service, sometimes in the face of the received wisdom of the time: 'I always wanted to change things... you had to try and advise without sounding as though you were lecturing them' LindaL. Sometimes it was concern about patient safety: 
... he was the director of the acute stroke unit. So I did go to him and say, we have to do something about swallowing. ThelmaT.

Career development was also an aspiration, although here the 'imposter syndrome' sometimes seems to have set in:

...jobs came up. There were five or six Chief 3 s and not one of them wanted it. ...Anyway, I thought I'd go for it... Anyway, I got the job. JayD.

There were 15 academics interviewing me. ...And they offered me the job and I heard this voice, which I later realized was my own saying, "And I have much pleasure in accepting, " and then sitting on the train going back to London thinking, "What have you done?" .JessW.

To an extent, these reflected the ambitions of the participants concerned, but also possibly an underlying feeling that there were others who were more qualified to take the posts and an element of luck in their successes.

Modesty: Participants gained in confidence as their careers progressed, although most continued to be diffident in claiming successes as their own. Team work was at the forefront of many reported achievements and most wore their leadership roles lightly, for example 'We always worked with our colleagues in OT and physio but it was never a formal arrangement. You did it because it was good practice' KathyF. Like several others, LindaL had set up the service she described, but still credited 
the team she had recruited for its success. The agency which participants reported, however, was key to their achievements, small or large and was occasionally acknowledged openly. JanetC: ... went to Canada. And did a locum at the Toronto General for about two, three months. while in one of her many moves, SallyK said:

... I had a small child and living opposite of me was somebody else with a child the same age. And she agreed to look after mine and we shared the proceeds of what I earned.

Some had achievements on a larger scale. Five had managed SLT services, two had led SLT university programmes, two had been Chairs of RCSLT and two had led major national charities. Modesty continued, even when exceptional achievement was recognised:

...to my surprise, was just before I retired, they gave me the Honours of College for just being an ordinary speech therapist. AmandaC.

In a final statement, after the audio recording had ended, but later added to the transcript, the 'lucky' JillC said:

...I was awarded an OBE in recognition of services to speech therapy. I recognise this was with the wonderful support of my colleagues...

\section{Summary}


Speech therapy largely attracted young middle class women. The participants in this study were products of their generation, class and gender and the majority conformed to the expectations of the times, however this does not give the full story. The reported concepts of self reflected similar influences of the wider society of the times, but were highly individual in terms of both their approaches to life and the impact of external circumstances. Each participant reported steps towards greater autonomy and agency within the constraints they recognised. Personal and professional good behaviour was a given for each. The restraint with which each reported their successes was tangible, again reflecting social expectations, but also personal styles regardless of whether success was personal or professional.

\section{Global theme 2. Professional stories.}

Figure 2 about here

\section{Speech then language therapy}

Over the late twentieth century, speech therapy changed from having a narrow focus on 'speech' to a growing recognition of the wide range of communication disabilities with which therapists were confronted. All participants identified a need to keep reflecting upon their knowledge and skills in order to meet the needs of their clients.

Mothers of invention: At the beginning of the period under study the range of client groups met by speech therapists was limited and, as UrsulaJ said, 'you just didn't deal with things that you couldn't give an answer to'. The Bulletin published case studies and 'what I did next' articles in an informal manner (Armstrong, 2005a). IJLCD and its predecessors demonstrated the way in which more academic papers 
changed over the period (Stansfield and Armstrong, 2016; Armstrong et.al, 2017). In the 1940s and 1950s came articles on adults with voice problems, stroke and stammering, while papers on paediatric cases also reported stammering, cleft palate, and 'dyslalia' (difficulties with articulation).

...it tended to be mainly articulation stuff and the lateral /s/. MegD (early 1950s)

The adults.... I just did the best I could. RuthS, (early 1960s)

From the late 1960s onwards editions increasingly identified language disorder, emerging conditions such as autism and technical advances in analysis and intervention for complex communication disorders. As they became more confident in their work, participants noted that there were many more communication difficulties than they had at first realised. The impact of language and swallowing, as well as speech difficulties associated with stroke, became increasingly identified and progressive neurological disorders became better understood. Many of the participants eventually specialised. KathyF was involved in 'the first centre for cochlear implant surgery'. For AltheaC it was oncology especially laryngectomy, for SusanD and ThelmaT, stroke and eventually for ThelmaT the resulting dysphagia. AbigailS and JanetC had wide ranging experience, but focussed on cerebral palsy. SelmaM, however, working in a rural area, considered herself to be a 'specialist generalist', saying that in any working week she might meet: 
...several ministers with dysphonia ... and if you've heard a free Presbyterian minister preaching! ...What else did we have? MND patients MS patients. Parki patients... cleft palate... SelmaM.

For all participants, there were times when necessity became the mother of invention. Sometimes it was travel logistics, having 'to work out things like boat timetables, ferry timetables' SelmaM, or riding between clinics for miles on a push bike 'with one of these little wicker baskets that you had. And in it, I would have my equipment. Which consisted, basically, of a set of small hand mirrors and a package of straws'. MegD.

Mainly it was ensuring that there was accommodation, equipment and especially assessment material. Up until the late 1960s there were no British published assessments and therapists made their own from whatever materials were available. The first formal tests were greeted with enthusiasm, despite their drawbacks, not least the assumption a target vocabulary item would be used:

I can remember when Edinburgh Articulation Test came out. "Oh, whoopee, a test. A standardized test." Except, of course, they showed it to Glasgow children [the picture of]- a chimney - and they said "lum". JanetC.

By the end of the 1960s more assessments were being produced. Renfrew selfpublished a suite of language tests (Renfrew, 1967) (the earliest, 1967 edition, of which was hand painted), widely used from the late 1960s onwards. Much more costly, the Reynell test (Reynell, 1972) was designed to assess both children's 
understanding and language expression, and became a core part of the speech therapists' tool kit.

Other equipment also gradually became more sophisticated. In cerebral palsy, for example there was much change between the late 1960s' do-it-yourself equipment to the early 1980s' computer aided technology:

...[the physiotherapist] ... made the thing to hold heads up. And it was all very, splints and goodness knows what then, but we invented a communication chart with pictures. JessW.

...this new door opened because we had communication technology...and children really eager to communicate, even if it was only hitting a switch to switch a light on. AbigailS.

Expanding knowledge: As they moved into their working lives, all the participants reported a need to enhance their knowledge base. Sometimes theory had been covered in College, but practical opportunities had been limited: cleft palate '...I actually went to appointments (when they had procedures and things) with them... Amazing' UrsulaJ. '...would you believe it, I switched to laryngectomies' JayD. JanetC decided to find out more about autism, because her experience did not match that of the theorists. 
...it was still the kind of 'refrigerator mother' attitude ...And I can remember meeting the father and her little brothers and thinking, "This family just don't fit this picture at all."

Linguistics was gradually introduced into the UK curriculum from the late 1960s. This challenged qualified therapists and all of the participants recognised that there was a change in emphasis once linguistic theory became widespread from the 1970s onwards. As RuthS said: 'I think when linguistics came into the profession, it made a huge difference'. 'Post-linguistics' stimulated a flurry of new learning, from short courses to more extended study, especially when new assessments, based in linguistic theory. By 1978, for example, Manchester University ran evening classes for qualified therapists, run by a lecturer 'originally appointed to the Linguistics Department to teach mainly on the speech and language therapy course and to do the course on LARSP' JessW.

On more traditional lines, seven of the participants undertook further academic qualifications at Masters and in one case, PhD level. One university Masters programme was established in 1971, explicitly to enable speech therapists to gain a higher qualification (Armstrong, 2005b). This was the degree taken by four of the participants. In order to study, CarolS gave up her job and 'sold my Mini [car]. I lived off that, you know?', while SusanD joined the programme in order to feel wellqualified as the profession began to move from diploma to degree entry in the 1970s:

[SLT] had become a degree course... So you would become a second class citizen if you were with a Diploma. 
The motivation and aspiration of each of these participants meant that they contributed to the increasing skills and knowledge base of not only themselves, but also the profession. RuthS wrote books ranging from what she called 'the most erudite', to one giving clinical suggestions. CarolS, JessW and JillC all published widely.

\section{Mentors and colleagues}

Patronage and power: Throughout its existence, SLT has benefitted from the sponsorship of external people. At a national level CST secured formal patronage from King George VI in 1948, as a result of his work with Lionel Logue. More recent long term political sponsors have included Lord Jack Ashley and John Bercow. The honorary fellowships of College reflect the wide range of other names giving substantial contributions to the work of the profession. These include paediatricians; paediatric and adult neurologists; neuro- and plastic surgeons; phoneticians and linguists; psychologists; and educators.

At a more local level, participants recognised both the frustrations and encouragement given by local colleagues in other professions. Every one of them spoke of individuals who had influenced their careers. Some were less than supportive:

the worst thing about it was the lack of support. I think probably some of the attitudes of the teachers. Some of them were wonderfully supportive, others thought you were just a waste of space UrsulaJ. 
I remember another consultant saying that he didn't think this chap needed any more speech therapy and before I knew what I was saying, I was saying, "How do you know?" Carols.

However one of the best things about the profession was also said to be colleagues:

..... the doctor who pioneered the cochlear implant programme ...he was so focused on his new service and quite passionate about it. KathyF ....the paediatrician, he was very for speech therapy.. And we ended up, we decided we'd start a preschool group, which we ran together. MillicentT.

Despite some reservations, therefore, it appears that the profession and these participants especially were, largely lucky in their sponsors.

Support and inspiration: While participants were generous about the contributions of many professions, they came to life when speaking of the speech therapists who had influenced them. Some senior members of the profession were mentioned by several participants, although none were seen as perfect. Anne McAllister (18921983), for example was seen in a positive light by some: ....she was such a learned woman, really, and knew so much. KathyF, but she could be acerbic:

... she said, "Suppose you were appointed to post in Persia. How would you set about organizing a speech therapy service?" And my jaw dropped and I 
said, "I don't know anything about it. I don't speak Persian." She looked at me witheringly and said, "I said Perthshire" MegD.

Joan van Thal (1900-1970), instrumental in drawing the warring speech therapy bodies together as CST in $1945^{\prime}$ '...was such a brilliant clinician ...[although she]... used to have us in hysterics, privately, because in order to detect nasal escape, she had invented a piece of apparatus which was a sort of jam jar' JessW. 'Catherine Hollingworth [1904-1999]... was, I suppose, inspirational' JanetC; and Betty Byers Brown (1927-1991) reflected the change from 'pre- to 'post-linguistics':

...Betty Byers Brown, she was a great person. I remember she said something about, when she left for America, speech therapists knew about speech, and when she came back from America, they'd discovered language...JayD.

Catherine Renfrew (1913-2002) was spoken of by several participants, possibly because of the tests she had published, but also because of her personality. She had a very dry wit.

...she had marvellous ideas, very imaginative. JillC.

...Catherine, so clever ...She was Plymouth Brethren. Never a drop passed her lips...except with [Althea's husband] Jim AltheaC. 
Many, however, were much less well-known names, but personally influential for the participants concerned, with the term 'inspirational' repeated frequently. What is clear from the narratives regarding speech therapy mentors is the way in which their memory lived on in participants' minds, for example: 'if anybody had ought to have the honour and glory of speech therapist, it's Rosemary. She was a superb clinician and she was a great inspiration to me' AmandaC. Recognition of this inspiration from mentors was something each participant clearly felt was important, in part as an influence on their own careers, thus contributing to the narratives of their lives, but also as founders and pioneers in developing the profession.

\section{Summary}

Each of the participants had many years' experience in the profession and the changes they reported in their working lives are mirrored in the professional publications over the period. The range of identifiable clinical fields expanded vastly between 1945, when the first participant qualified, to 2008 when the last participant 'officially' retired. The influence of medical and psychological practitioners, while vital to the extending knowledge bases of the profession and professionals, was overtaken by the rise of the linguist and linguistics from the 1970s onwards. The participants saw their work as interesting and intellectually demanding, theorising about their professional practice and valuing opportunities to learn as new knowledge became available. Material from the RCSLT archive, as well as personal reports by the participants, indicates that the professional body took advantage of positive male sponsors, in order to promote professional development. The fact that majority of people at every level of the profession were women, however, gave 
female role models which encouraged these participants' professional ambitions to be pursued.

\section{Global theme 3. Political stories.}

Figure 3 around here

Archive materials indicate that there were three stages in the development of the post-war profession. The first was an apparent acceptance of early patriarchal attitudes to the profession as a female vocation, requiring guidance and regulation by the more established, predominantly male medical profession. This was used in the interests of the profession as it established its existence. Next, unlike similar professions, speech therapy demanded autonomy, which was, reluctantly, accepted by regulatory bodies. The profession proved itself able to function independently and for a time SLT benefitted from the more benign policy environment in the 1970s. Thirdly, the growth in anti-professionalism of the Thatcher and to some extent the Blair governments, caught speech therapy in its wake leading to political activism.

\section{Post war realities}

Identity: Archive material demonstrates that speech therapy had bent to pressure to joining the NRMAS-ST register, but registration was increasingly an issue of professional concern throughout the 1950s. The Cope Committee, with a preponderance of medical members, reported in 1951. It recommended statutory regulation, under medical control, of a range of 'medical auxiliaries' (BMJ, 1951). This was unacceptable to the profession, which did not see itself as auxiliary to 
either medicine or education. Growing increasingly self-assured, CST withdrew from the NRMAS-ST and published its own register from 1955. Even more contentious was the planning for a Council for Professions Supplementary to Medicine (CPSM). Despite heavy government lobbying, CST declined to join the CPSM in 1960 (Editorial, 1960), a decision which continued to be in force until the creation of the Health Professions Council. ${ }^{1}$

Policy and practice: The after-effects of the Second World War were felt for some considerable time after the establishment of CST in 1945. The earliest qualified of the participants in this study, SallyK, on commencing her training in 1944 said that shortly after moving lodgings: 'a bomb went through the roof over one of the beds... one or other of us would have had it'. JoanW, completing her training in 1945 reported sitting exams as bombs fell in London. Participants also noted that it took a long time to restore the infrastructure, thus, well into the 1950s:

I mean Newham was bombed almost ... When I came, most of it was in ruins AmandaC.

The influence of the immediate post-war accomplishment of social change was profound: national policy initiatives affected the profession directly. Of these, the most radical was the National Health Service, established in 1948. For children another equally radical change came with the $1944(1945,1947)$ Education Acts. These Acts required all local authorities to provide free health care for school children and established the school health service. Following this, Wilkins (1952)

\footnotetext{
${ }^{1}$ Reference to all primary sources is available from the author on request
} 
noted a rapid increase in the number of school clinics with consequent expansion of employment opportunities for speech therapists within 'school health'. The Acts also required all local authorities to provide special education for children with a range of specified disabilities including speech disorder, although all excluded 'severely subnormal' children from educational provision, they being considered 'ineducable'. It appeared that some physically disabled children were also excluded:

I lived in a nurse's home and the children that, I knew even then it was wrong, they've been abandoned often by their parents. They were children with huge physical problems who've been admitted for some operation or other and then just never collected. It was heart-breaking. RuthS.

Despite the small number of speech therapists in the UK when the earliest participants in this study qualified, participants commented on the need to appear single, in order to gain employment. The 'marriage bar', which banned married women from working in education, had been officially removed by the Education Acts, but in 1950s Scotland at least, education services still pressured women teachers (and speech therapists employed in the school health service) to 'retire' on marriage.

... we had to hide our engagement rings ..... before we went for an interview. And having secured a place with Child Guidance, I had to resign a year later when I got married. UrsulaJ. 
... a contemporary of mine says she still has the letter, she had to apply to work on after she married. She has the letter agreeing to that. ThelmaT.

In addition, as the majority who had children gave up work for a time, the numbers qualifying did not rapidly translate into a much larger workforce.

The liberal agenda: In 1971 in England and Wales (and 1974 in Scotland), all children finally became entitled to education, with further changes and a presumption of 'inclusive' education coming in the wake of the 1978 Warnock Report and subsequent 1981 Education Act. While participants made little direct reference to this, in discussing their work it was clear that children were increasingly integrated into mainstream schools and the terminology had changed to 'special needs':

...I've never really worked in anything else but ordinary schools UrsulaJ.

one of the community paediatricians who was based in [hospital], and she used to go out to the different schools and visit the kids that had special needs SelmaM.

It was equally clear that participants enjoyed the work in educational settings and found their experiences rewarding.

While NHS change was a constant throughout the period under study, some changes affected speech therapists more directly than others. In particular, an NHS re-organisation in 1972, creating Area Health Authorities paralleled the first, and to 
date only, government report on speech therapy (the Quirk Report, DES, 1072). 'Quirk' made recommendations which, being accepted by government, transformed the profession both in the short and long term. Prior to Quirk, speech therapy had existed in two separate environments, those of 'school health', with education terms and conditions of service and NHS, with health service contracts. The changes implemented as a result of Quirk were complemented in 1975 by the Halsbury Report (DHSS,1975), which made definitive recommendations not only on the employment structure but also the pay of speech therapists. Directly or indirectly, these reports impacted the lives of almost all of the participants. By 1974, most therapists were employed under the same (NHS) employment terms and conditions.

'Quirk' also meant that speech therapy education was transformed in the 1970s, after some substantial challenges along the way. Heads of speech therapy schools spent many hours working to join the universities, for example:

....[University A] rejected her. But actually, the move to [University B] was good because once we'd gone, a lot of all the other paramedics joined us. It got a good name right from the start CarolS.

I, like a dog with a bone, decided we would jolly well go and see... So we battled for a few years and finally convinced [University C] that they wanted us JillC.

The first national advisor (another Quirk recommendation) was Betty Byers Brown who rapidly made her presence felt in the Department of Health: 
“.... B cubed [BBB] said so and so" ...and I was allowed to say what we wanted in the way of speech therapy accommodation in the hospital and in the clinics too... AmandaC.

Participants managing services as a result of the new career structure used the Quirk Report to increase the numbers employed in their areas, for example:

...well that Quirk Report, it was great. We had something we could actually refer to help us make our case. JayD.

Thus, the 1970s were not only a time of academic change, but also the second social revolution in terms of service development and expansion for the speech therapy profession.

\section{Because we're worth it}

Pay: Pay was an issue for the profession from its inception. The early registers indicated that where speech therapists were working in hospitals, they were frequently 'honorary' (i.e. unpaid) and where salaries were earned, they were low even for the times. MillicentT, a rural therapist said ' ... the pay was minuscule, didn't even pay the ferry'. JessW, reported her first year's pay 'I've still got the receipt. I have, it was $£ 402$ per annum’. AbigailS, who had worked abroad briefly before taking up her first substantive post said: 
...what we got for a month working in the NHS in Glasgow was I think a quarter of what we'd received in Canada. So we were in tears.

Job adverts throughout the 1950 s and 1960s continued to demonstrate poor pay, with salaries in 1952 the equivalent today of £8-10,000; $1962 £ 8-12,500 ; 1972 £ 9$ 15,000, until the Halsbury Report made a direct and immediate impact on salaries:

we had this big jump in the 70s and I remember one of the girls ...she was a brilliant speech therapist. Her salary tripled at that time AmandaC.

By 1978, however, the 'winter of discontent' led to the Labour government setting up the Clegg Commission to compare pay across different sectors. AmandaC reported the intervention of the new (Conservative) Secretary of State, which resulted in speech therapy comparators being changed:

...they decided we were the same as telephonists. ...l lived in this constituency of Patrick Jenkin who was the Secretary of State... he was just so helpful

The Commission was abolished by the UK Conservative government the following year.

Equality: A major campaign, mentioned by many of the participants was a longrunning and ultimately (mostly) successful case claiming 'equal pay for work of equal value'. This case, brought in 1986 by Pam Enderby, was supported by the ASTMS union and the Equal Opportunities Commission. Despite improvements in pay, there 
remained a discrepancy of around forty percent between pay rates of the mainly male seniors in clinical psychology and pharmacy and senior women in speech therapy. The case took a total of seven years, involving 2,000 applicants (including at least two of the participants in this study) and sixteen test cases. There were several defeats in the British courts where the government defended and won, but these were followed by eventual success in the European Court of Justice in 1993. 350 later test cases were won, although a small number, including AmandaC's, were unsuccessful, with the Union apparently judging that these individuals could be sacrificed for the greater good.

...the Department of Health had said they would hold up all the rest of the people getting their money if they argued the case for $\underline{\text { us. }}$. And so they just ditched us...Totally outrageous. AmandaC,

Overall, however, this was an unusual success, increasing speech therapy and other women NHS staff's pay across the board and, at least in principle, levelling the pay field for men and women across the NHS.

Health service pay and conditions are continuing issues, with the final one mentioned by these participants in this study being Agenda for Change, introduced in 2004. This was another attempt to standardise (and control) pay banding, in part influenced by the equal pay success (Hastings, 2007). This initiative was sold as being able to deliver fair pay for non-medical staff based on the principle of equal pay for work of equal value. This came at the end of their careers for the few participants it affected, but the experience seemed less than benign. 
...it was really bad because it put one therapist against another. It set one profession against another. It set different areas against each other. KathyF

Nevertheless, this structure remains the basis of NHS employment.

\section{Summary}

Participants benefitted from legislative enablers, such as health and educational reform and equal rights legislation, but also from the social changes which enabled women to play a more visible role in the workforce and society. They did not report strong political identities, but a strong sense of justice, which could and did lead to political action when something was perceived to be unfair.

\section{Conclusion}

This paper presents the first oral history of speech therapy carried out in the UK. As such, it offers a unique insight into the way in which some of the earliest postSecond World War-registered practitioners experienced their lives as women professionals. The oldest participants joined a profession of fewer than 300 people, almost all women, although the era of second-wave feminism (Gluck, 2013) appeared, if not to have passed them by, at least to have been tangential to their perceptions of their daily lives. The political changes throughout the period, including the major social policy initiatives of the post-war Labour government, the subsequent liberalisation of education and equality legislation and the resulting changing expectations of the balance between domestic and professional lives were more overtly indicated in the narratives of the participants. The women in this study 
can, therefore, in one view be seen as typical of their generations. In other ways, however, they are all exceptional. One of the most extraordinary elements to the stories was the modesty with which participants reported their achievements. Some were small and personal, some of national importance, but nevertheless across each of the transcripts, even with encouragement, their voices indicated only a quiet satisfaction with the directions in which their careers had taken them. 


\section{References}

ABRAMS, L. (2016) Oral history (2 ${ }^{\text {nd }}$ edition). (Abingdon: Routledge).

ARMSTRONG, L. (2005a) 'The swinging sixties'. Bulletin, 642, 10-11.

ARMSTRONG, L. (2005b) 'A volatile decade'. Bulletin 642, 14.

ARMSTRONG, L. and STANSFIELD, J. (1996) A content analysis of the journal of the BSST I: Spotlight on 'Speech'. EJCD 31, 91-105.

ARMSTRONG, L. STANSFIELD, J. and BLOCH, S. (2017) Content analysis of the professional journal of the RCSLT III: into the $21^{\text {st }}$ century, 1966-2015. IJLCD 52(6), 681-688.

ATTRIDE-STIRLING, J. (2001) 'Thematic networks: an analytic tool for qualitative research', Qualitative Research, 1:3, 385-405.

BRITISH MEDICAL JOURNAL. (1951) Medical Auxiliaries in the National Health Service: proposed statutory registration'. BMJ, (1:4711 21.4.51), 877-879

BROWN, B. (1971) Speak for yourself (Reading: Educational Explorers).

COPE, V.Z. (1945) 'The real and the ideal' Speech 9(1), 4-6.

Department of Education and Science (1972) Speech therapy services (the Quirk Report) (London:HMSO).

DEPARTMENT of HEALTH and SOCIAL SECURITY (1975) Report of the committee of inquiry into the pay and related conditions of the professions supplementary to medicine and speech therapists. (the Halsbury Report) (London:HMSO).

DUCHAN, J (n.d.) History of speech-language pathology.

http://www.acsu.buffalo.edu/ duchan/new history/overview.html [Accessed

23.10.19].

DYHOUSE, C. (2016) 'Education'. in Ina Zweiniger-Bargelowska (ed) Women in twentieth century Britain (Abingdon:Routledge), 119-133

EDITORIAL (1945) Speech 9(1), 3.

EDITORIAL. (1960) 'Statutory registration'. Speech Pathology and Therapy 3(2), 5154.

GLUCK, S (2013) 'From California to Kufr Nameh and back'. In A. Sheftel \& S. Zembrzycki (eds). Oral history off the record (New York:Palgrave), pp.25-42.

HASTINGS, S. (2007) Speaking out for change. (London:TUC). 
HEWERDINE, E. (2014). Memoirs of a peash ferapis (New York:Vanguard Press). HOLLINGWORTH, C. (1993) Building bridges (Durham:Pentland Press).

KINGDON-WARD, W. (1948) 'Speech therapy. Development and training in Britain'. In Clive Sanson (ed), Speech of our time (London:Hinrichsen), pp.199-201.

RENFREW, C. (1967) Test battery (Oxford:Self-published).

REYNELL, J. (1969). Reynell developmental language scales (London:NFER).

ROBERTSON, S. KERSNER, M. and DAVIS, S. (1995) A history of the College 1945-1995 (London:RCSLT).

ROCKEY, D. (1980) Speech disorder in nineteenth century Britain (London:Croom Helm).

SHULMAN, A. (2015) 'Story ownership and entitlement' in Anna de Fina and Alexandra Georgakopolou. The handbook of narrative analysis (London:John Wiley), pp.38-56.

STANSFIELD, J. and ARMSTRONG, L. (2016) Content analysis of the professional journal of the CST II: coming of age and growing maturity, 1946-65. IJLCD 51(4), 478-86

WILKINS, J. (1952) 'Speech therapy in Great Britain'. Quarterly Journal of Speech 9 (1), 7-8.

WILKINS, J. (1992) A child's eye view (Bishop Aukland:Pentland Press)

WITZ, A. (1992) Professions and patriarchy (Abingdon: Routledge).

YOW, V. (2015) Recording oral history (3rd edition). (Lanham, Maryland: Rowman and Littlefield). 
Table 1: Thematic network analysis stages summary (Attride-Stirling, 2001)

Analysis stage A. Breakdown of the text

Step 1: code material

Step 2: identify themes

Step 3: construct thematic networks

Analysis stage B. Exploration of the text

Step 4: Describe and explore thematic networks

Step 5: summarise thematic networks

Analysis stage $\mathrm{C}$. Integration of exploration

Stage 6: interpret patterns

Table 2: Participants (pseudonyms)

\begin{tabular}{|l|l|}
\hline Name & Qualification decade \\
\hline JoanW & 1940 s \\
SallyK & \\
\hline AmandaC \\
JanetC \\
JayD & \\
JessW & \\
JillC & 1950s \\
LindaL & \\
MegD & \\
MillicentT & \\
RuthS & \\
SusanD & \\
ThelmaT & \\
UrsulaJ & \\
\hline AbigailS & \\
AltheaC & \\
CarolS & KathyF \\
SelmaM & \\
\hline
\end{tabular}




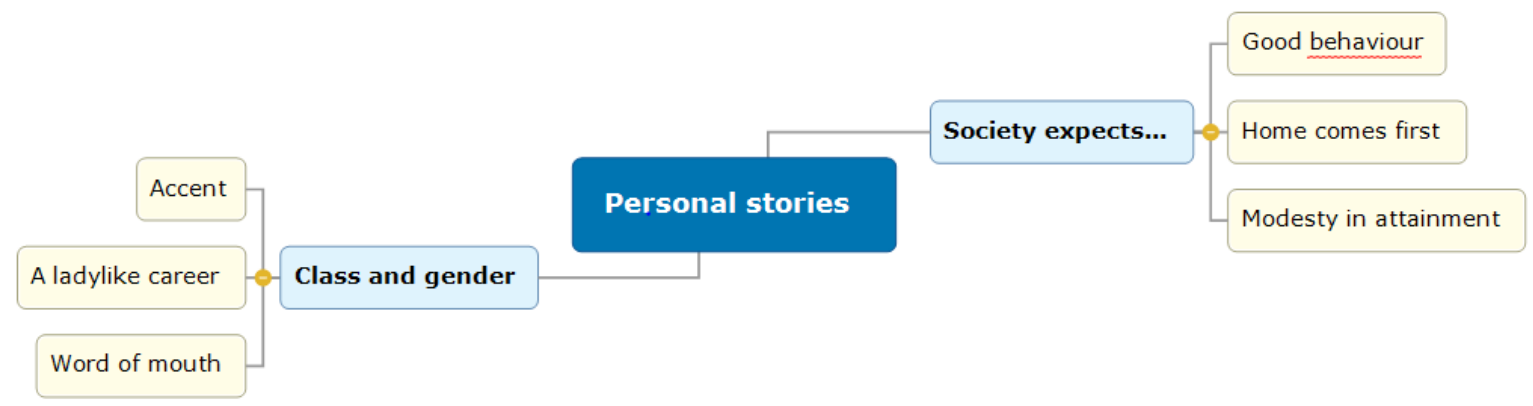

Figure 1: Thematic network. Personal stories

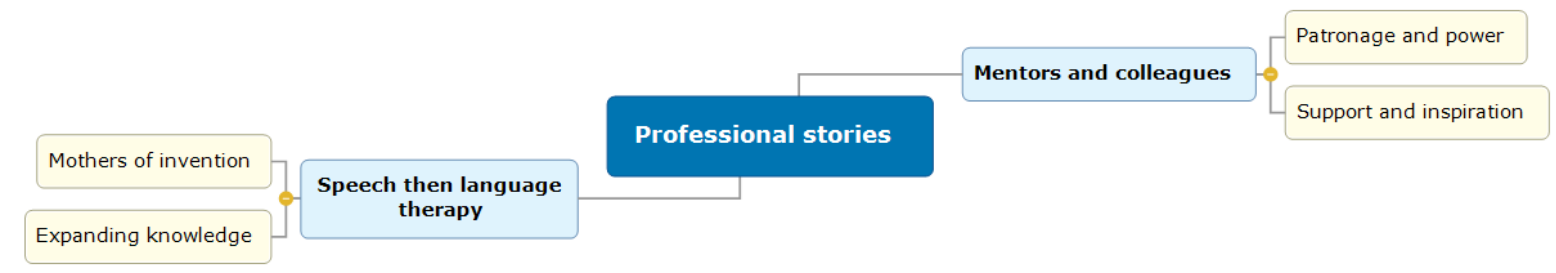

Figure 2: Thematic network. Professional stories

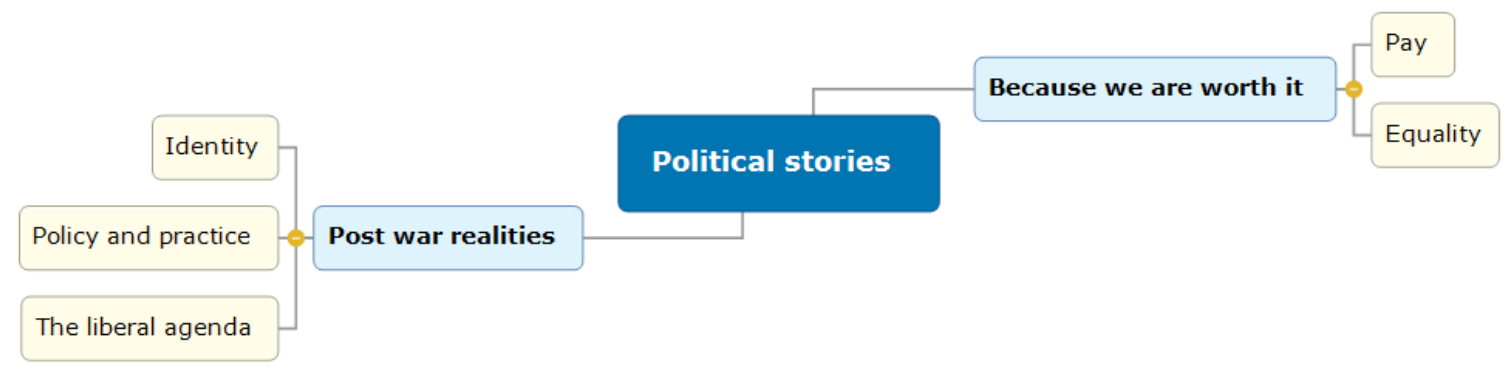

Figure 3: Thematic network. Political stories 